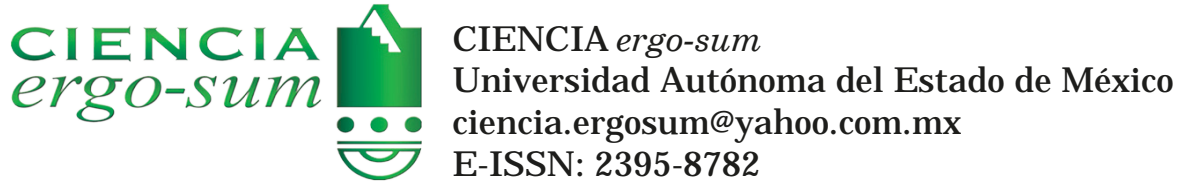

\title{
Evaluador inteligente de daño fenológico en la planta de trigo
}

Moreno Gutiérrez, Silvia Soledad; Toriz Palacios, Alfredo; López Pérez, Sócrates; Ruiz Vanoye, J orge Alberto Evaluador inteligente de daño fenológico en la planta de trigo CIENCIA ergo-sum, vol. 26, núm. 3, noviembre 2019-febrero 2020| e64

Universidad Autónoma del Estado de México, México

Esta obra está bajo una Licencia Creative Commons Atribución-NoComercial-SinDerivar 4.0 Internacional.

Moreno Gutiérrez, S. S., Toriz Palacios, A., López Pérez, S. y Ruiz Vanoye, J . A. (2019). Evaluador inteligente de daño fenológico en la planta de trigo. CIE NCIA ergo-sum, 26(3). https://doi.org/10.30878/ces.v26n3a7 


\title{
Evaluador inteligente de daño fenológico en la planta de trigo
}

Intelligent evaluator of phenological damage in the wheat plant

Silvia Soledad Moreno Gutiérrez

Universidad Autónoma del Estado de Hidalgo, México

silviam@uaeh.edu.mx

Recepción: 04 de diciembre de 2017

Aprobación: 20 de junio de 2018

Alfredo Toriz Palacios

Universidad Popular Autónoma del Estado de Puebla, México

alfredo.toriz@upaep.mx

Sócrates López Pérez

Universidad Autónoma del Estado de Hidalgo, México

lopezs@uaeh.edu.mx

Jorge Alberto Ruiz Vanoye

Universidad Popular Autónoma del Estado de Puebla, México

jorge@ruizvanoye.com

\section{RESUMEN}

El cambio climático en el planeta ha afectado la producción mundial de trigo y los pronósticos aseguran que estos cambios y efectos serán mayores conforme pase el tiempo. Considerando la importancia de este cereal como alimento de la dieta básica de los seres humanos, se propone una nueva forma de evaluación del cultivo que permita pronosticar el daño probable por etapa fenológica por medio de una red neuronal artificial entrenada con datos históricos del comportamiento climático global e impacto fenológico. Un sistema de resultados interpreta la salida y constituye la interfaz de usuario. La propuesta fue validada y mostró su capacidad de generalización alcanzando alta precisión de $84 \%$, por lo que se considera adecuada.

Palabras ClaVe: redes neuronales artificiales, estrategia tecnológica, fenología del trigo, evaluación, cambio climático.

\begin{abstract}
Climate Change on the planet has affected the world wheat production and forecasts ensure that these changes and effects will be greater over time. Considering the importance of this cereal as a basic diet of human beings, this work proposes a new form of crop evaluation that allows to forecast probable damage by phenological stage, through an Artificial Neural Network trained with historical data of global climatic behavior and phenological impact. A results system interprets the output and constitutes the user interface. The proposal was validated, showed its generalization capacity and reached high precision of $84 \%$, so it is considered adequate.
\end{abstract}

KEYWORDS: artificial neural networks, technological strategy, wheat phenology, evaluation, climate change.

\section{INTRODUCCIÓN}

El trigo es un alimento clave para la supervivencia humana al formar parte de la dieta básica y, junto con el maíz y el arroz, cubre aproximadamente 50\% de las calorías consumidas en el planeta; además ocupa la segunda posición como cereal básico de mayor producción y consumo internacional (Reynolds et al., 2016).

No obstante, el sector cerealista enfrenta una de las más fuertes barreras para la competitividad: el cambio climático (CC) (Field et al., 2014). Esta serie de anomalías en las condiciones atmosféricas respecto a los registros 
históricos tienen un origen antropogénico que inició con la sociedad moderna y su industrialización (Serrano, 2015); por ello, sus principales consecuencias son debido a incrementos de la temperatura global (Singh y Singh, 2015), cambios en los patrones meteorológicos y por el grave impacto en la agricultura a causa de la estrecha relación entre el desarrollo de los cultivos y las condiciones climáticas óptimas (Reeves et al., 2016).

El Grupo Intergubernamental de Expertos sobre el Cambio Climático (IPCC), creado en 1988 con el objetivo de evaluar integralmente el estado del conocimiento científico, técnico y socioeconómico del cambio climático (con base en la literatura científica y técnica publicada por homólogos), ha dado evidencias de que la temperatura se ha incrementado cerca de $2{ }^{\circ} \mathrm{C}$ y de que los ciclos de lluvias o sequías son más intensos e irregulares, por lo cual la relación entre agricultura y cambio climático ha alterado la producción de trigo a través de los cambios en los componentes de su fenología.

Los resultados de estas evaluaciones publicados a través de cinco informes de alto grado de confianza (el último en 2014) identifican al trigo como uno de los cultivos más afectados en su producción y más vulnerables en su desarrollo fenológico (desarrollo en función del clima), del cual la especie Triticum aestivum es la más afectada (Jones y Phillips, 2016), situación que contribuye al riesgo de la seguridad alimentaria.

El agricultor cerealista considera la evaluación del desarrollo de sus cultivos una prioridad y emite un diagnóstico apoyado generalmente en el monitoreo manual (técnica tradicional empírica que consiste en elegir algunas plantas, retirarlas del suelo y observarlas), Rawson y Macpherson (2001). Sin embargo, debido a su naturaleza no probabilística, esta técnica no permite generalizar sus resultados (Nieves-Hurtado y Domínguez-Sánchez, 2009); a pesar de arrojar diagnósticos poco confiables, el agricultor la utiliza aún en grandes extensiones de siembra.

El cambio climático constituye, además, una amenaza para el desarrollo económico, que ya ha experimentado pérdidas con variaciones en cada país, volatilidad de precios en la Unión Europea e incremento de las importaciones en algunos países de África y América Latina (Butt et al., 2016; Trnka et al., 2015).

Por lo anterior, el sector cerealista ha considerado diversas propuestas e investigaciones con el propósito de acceder a un mayor conocimiento del comportamiento del cultivo y reducir la incertidumbre, así como enfrentar con eficiencia y eficacia el reto del cambio climático. A continuación presentamos algunos de los trabajos más representativos.

a) Los modelos de simulación de cultivos son sistemas capaces de crear escenarios futuros y analizar posibles comportamientos del cultivo ante las condiciones climáticas; de manera general muestran aciertos, aunque también deficiencias durante la simulación de altos incrementos de temperatura (Gaydon et al., 2017).

Entre los más utilizados se encuentra el CERES para trigo (Gallo, 2015), a pesar de su funcionamiento inadecuado debido básicamente a su necesidad de grandes cantidades de información en ocasiones no disponibles (Zheng et al., 2017). El Simulador de Sistemas de Producción Agrícola (APSIM, por sus siglas en inglés) tiene resultados satisfactorios, pero requiere ajustes para países asiáticos (Gaydon et al., 2017).

b) Los modelos fenológicos y predictivos, capaces de descubrir información del efecto del cambio climático sobre el desarrollo fenológico del trigo ( $\mathrm{Lv}$ et al., 2016), han sido analizados y concluyen que hay incertidumbre en la representación de efectos por altas temperaturas (Asseng et al., 2015) y enfoques exclusivamente locales (Arnell, 2016). Los modelos de este tipo efectúan predicción de incidencias en cultivos (Arkeman et al., 2014) y predicción del desarrollo fenológico (Lv et al., 2016), todos ellos basados en técnicas estadísticas o matemáticas.

Las técnicas de Inteligencia Artificial (IA) se han convertido en un medio que ha apoyado al sector cerealista en tareas de predicción y clasificación (Gutiérrez et al., 2018). Las RNA constituyen la técnica de inteligencia artificial más explotada en el sector debido a su alta precisión y a su capacidad en el manejo de incertidumbre; es decir, de procesar datos incompletos o borrosos de alta variabilidad (Palmer-Pol y Montaño-Moreno, 1999). 
Como referencia, una RNA es un modelo integrado por varios nodos cuyo funcionamiento se basa en los principios de las neuronas biológicas para reproducir su aprendizaje. Cada nodo o neurona tiene uno o más datos de entrada que al combinarse entregan un resultado que es evaluado por una función de activación para finalmente obtener la salida. La interconexión de dos o más neuronas dan lugar a una capa y la interconexión de varias capas conforman una RNA (Yegnanarayana, 2009).

Además de los modelos mencionados, son diversas las investigaciones que de manera experimental han estudiado el desarrollo fenológico del trigo e identificado etapas de mayor sensibilidad. Algunos de estos trabajos científicos y sus hallazgos se mencionan a continuación.

Las heladas producen daño al cultivo cuando son radiantes (Crimp, 2016), que es mayor luego de la etapa de emergencia (Frederiks et al., 2015); ante las bajas temperaturas, la mayor sensibilidad es en el espigado y llenado de grano (Ji et al., 2017), al igual que con temperaturas altas que además reducen el rendimiento en 79\% (Pimentel et al., 2015).

El trigo saudí bajo estrés por calor disminuye en crecimiento y parámetros fisiológicos (Boutraa et al., 2015) y el trigo de primavera ante la sequía muestra mayor plasticidad fenológica durante la emergencia, así como mayor sensibilidad en la antesis (Sanad et al., 2016). En ambiente árido existe relación entre índices de crecimiento y rendimiento al inicio de la fase de reproducción, y la antesis es la etapa más sensible a la sequía y a la fecha de siembra (Ihsan et al., 2016). Estos estudios aportan información local útil para la toma de decisiones del agricultor.

El estado del arte, sin embargo, no muestra propuestas que tengan un enfoque global y que estén basadas en técnicas de alta precisión que apoyen al agricultor en el monitoreo del desarrollo de sus cultivos u ofrezcan un panorama expresado en lenguaje sencillo y sean accesibles en términos de tiempo por cada etapa fenológica.

Por lo anterior, el documento propone un evaluador inteligente de daño fenológico de la planta de trigo basado en una RNA de alta precisión con enfoque global, cuyo diagnóstico será emitido por cada etapa de desarrollo a través del sistema de resultados. La propuesta ofrece al agricultor información precisa y oportuna de apoyo en la toma estratégica de decisiones orientada al mejoramiento sustentable de la producción.

\section{Metodología}

El evaluador propuesto se compone de dos elementos: el primero consiste en una RNA y el segundo en un sistema de resultados. La RNA evalúa la respuesta del cultivo ante las condiciones climáticas dadas, identifica etapas vulnerables y diagnostica daño fenológico (en su caso). El sistema de resultados, por su parte, constituye la interfaz entre el evaluador y el usuario, además es encargado de interpretar el diagnóstico final; previamente, analiza la permanencia de condiciones climáticas adversas e identifica la causa de daño. El diagrama general se muestra en la figura 1.

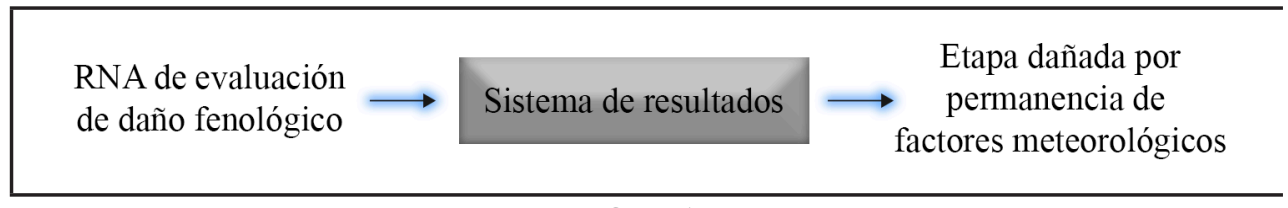

FIGURA 1

Diagrama general del evaluador inteligente de daño fenológico

Fuente: elaboración propia.

El modelo considera cuatro ambientes de desarrollo: húmedo, subhúmedo, semiárido y árido, además de la escala Zadoks de desarrollo fenológico del trigo, cuyas etapas consideradas son únicamente las ocho primeras: germinación, emergencia, macollaje, encañado, envainado, espigado, antesis, grano lechoso y finalmente ocho probables causas de daño: estrés hídrico, heladas, variación de temperaturas (altas o bajas), humedad, baja radiación solar, lluvias o vientos fuertes. 
En el desarrollo de la propuesta se empleó un total de 68685 patrones o registros climáticos (de 10 variables cada uno) extraídos de la base de datos tutiempo.net y provenientes de diversas regiones del mundo de 1990 a 2017, donde 79\%, es decir, 53585 fue empleado para el aprendizaje y 21\% restante 15100 para validarla.

\section{Composición y FUnCionamiento de LA RNA}

\section{1. Arquitectura}

La RNA se basa en un modelo Adaline monocapa con diez variables meteorológicas de entrada: temperatura media $\mathrm{T}\left({ }^{\circ} \mathrm{C}\right)$, temperatura máxima $\mathrm{TM}\left({ }^{\circ} \mathrm{C}\right)$, temperatura mínima $\operatorname{Tm}\left({ }^{\circ} \mathrm{C}\right)$, humedad relativa media $\mathrm{H}(\%)$, precipitación total de lluvia y/o nieve derretida PP $(\mathrm{mm})$, visibilidad media $\mathrm{VV}(\mathrm{Km})$, velocidad media del viento $\mathrm{V}(\mathrm{Km} / \mathrm{h})$, velocidad máxima sostenida del viento $\mathrm{VM}(\mathrm{Km} / \mathrm{h})$, indicador de lluvia o llovizna RA e indicador de niebla FG. Cada registro o patrón climático de entrada está compuesto por 10 datos correspondientes a cada una de estas variables.

El modelo consta de ocho variables de salida (neuronas) y cada una coincide con una de las primeras ocho etapas fenológicas del trigo (E0 a E7) (figura 2).

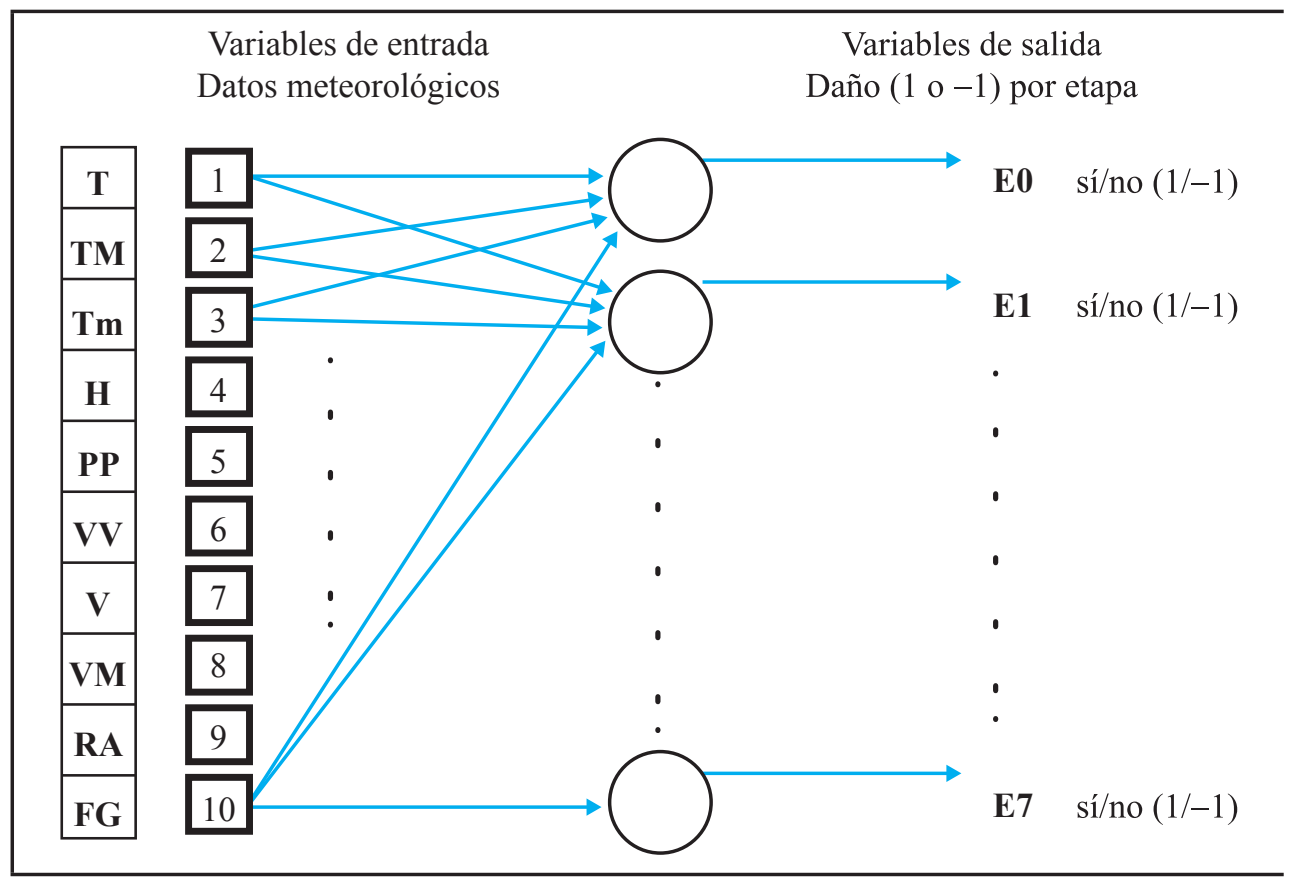

FIGURA 2

Arquitectura de la RNA

Fuente: elaboración propia.

En caso de existir daño en alguna etapa, la neurona correspondiente se activará mostrando 1 como salida y-1 en caso contrario.

Los datos de entrada y su relación con el daño fenológico se exponen en el apartado siguiente.

\section{2. Análisis del daño fenológico}

Previo al aprendizaje y validación de la RNA, se desarrolló el análisis a través del cual se estableció la relación entre clima, fenología del trigo y daño probable. 
El clima se representó a través de las diez variables de entrada. Por su parte, la fenología y daño en alguna etapa se basó en los criterios expuestos por la Organización de las Naciones Unidas para la Alimentación y la Agricultura (FAO, por sus siglas en inglés), en su manual Trigo Regado (Rawson y Macpherson, 2001), considerados tanto para el aprendizaje como para la validación.

Se analizó el daño posible para cada una de las ocho etapas en cada uno de los cuatro ambientes, debido a cada una de las ocho causas mencionadas. Se considera su aparición cuando alguna variable climática se presenta consecutivamente o combinada con otra o cuando excede los límites superiores o inferiores soportados por la planta. La determinación de la causa se basó en la variable climática, número de días que permaneció y etapa del cultivo.

\section{2. 1. Desarrollo del análisis}

Para identificar daño por estrés hídrico (falta de agua en la planta), se empleó el método de Lafitte que en tres pasos permite identificar:

a) Cantidad de agua empleada por el cultivo diariamente ( $\mathrm{mm})$ (AEC). $A E C=$ demanda evaporativa $\times$ coeficiente de evapotranspiración (cuadro 1 y cuadro 2 )

b) Cantidad de agua disponible estimada en el suelo antes de iniciar el estrés hídrico (ADS). ADS = Humedad en el suelo momento actual $(\mathrm{mm})$ - humedad en el suelo, 50\% capacidad de campo (tabla 1$)$

c) Total de días que crece el cultivo sin lluvia ni riego antes de sufrir estrés (DAE). $D A E=A E C \mid A D S$

Este resultado permite al agricultor prevenir daño en el cultivo y la propuesta le informa de esta posibilidad con siete días de anticipación.

\section{CUADRO 1}

Demanda evaporativa $(\mathrm{mm} /$ día $)$

\begin{tabular}{lccc}
\hline mm de evaporación & \multicolumn{3}{c}{ Temperatura media diaria $\left({ }^{\circ} \mathrm{C}\right)$} \\
\cline { 2 - 4 } por día en trópico & $10-16$ & $17-23$ & $24-30$ \\
\hline Húmedo & $3-4$ & $4-5$ & $5-6$ \\
Subhúmedo & $3-5$ & $5-6$ & $7-8$ \\
Semiárido & $4-5$ & $6-7$ & $8-9$ \\
Árido & $4-5$ & $7-8$ & $9-10$ \\
\hline
\end{tabular}

Fuente: elaboración propia con datos de Rawson y Macpherson (2001).

\section{CUADRO 2}

Coeficiente de evapotranspiración

\begin{tabular}{lcc}
\hline Etapa de crecimiento & Escala Zadoks & Coeficiente de cultivo \\
\hline Fase vegetativa & E1.0-E1.3 & 0.3 \\
Macollaje & E1.3-E3.0 & 0.8 \\
Encañado & E3.0-E6.8 & 1.0 \\
Llenado del grano & E6.8-E8.7 & 0.5 \\
\hline
\end{tabular}

Nota: La escala Zadoks identifica cada etapa con un número entero. Los valores decimales refieren estados de desarrollo intermedios entre cada etapa. Fuente: elaboración propia con datos de Rawson y Macpherson (2001). 
TABLA 1

Humedad en el suelo

\begin{tabular}{|lcccc}
\hline $\begin{array}{l}\text { Por encima de la capacidad } \\
\text { de campo }\end{array}$ & $\begin{array}{c}\text { Sale agua al golpear } \\
\text { el suelo }\end{array}$ & $\begin{array}{c}\text { Libera agua si el } \\
\text { suelo es amasado }\end{array}$ & $\begin{array}{c}\text { Posible escurrir El suelo intacto tiene } \\
\text { agua del suelo }\end{array}$ & brillo acuoso \\
\hline $\begin{array}{l}\mathbf{7 5 - 1 0 0 \%} \text { de capacidad de } \\
\text { campo }\end{array}$ & $\begin{array}{l}\text { Se une ligeramente, } \\
\text { puede formar una bola }\end{array}$ & $\begin{array}{l}\text { Forma una bola que } \\
\text { se rompe fácilmente }\end{array}$ & $\begin{array}{l}\text { Forma una bola } \\
\text { muy flexible }\end{array}$ & $\begin{array}{l}\text { Forma una cinta plana } \\
\text { entre los dedos }\end{array}$ \\
Agua disponible & $\pm 70 \mathrm{~mm}$ & $\pm 110 \mathrm{~mm}$ & $\pm 155 \mathrm{~mm}$ & $\pm 200 \mathrm{~mm}$ \\
$\begin{array}{l}\mathbf{5 0 - 5 \%} \text { de capacidad de } \\
\text { campo (estrés probable) }\end{array}$ & $\begin{array}{l}\text { Parece seca, no forma } \\
\text { una bola cuando } \\
\text { escurre }\end{array}$ & $\begin{array}{l}\text { Forma una bola que } \\
\text { no se mantiene }\end{array}$ & $\begin{array}{l}\text { Forma una bola } \\
\text { algo plástica }\end{array}$ & $\begin{array}{l}\text { Forma una bola y una } \\
\text { cinta entre los dedos }\end{array}$ \\
Agua disponible & $\pm 50 \mathrm{~mm}$ & $\pm 80 \mathrm{~mm}$ & $\pm 110 \mathrm{~mm}$ & $\pm 140 \mathrm{~mm}$ \\
\hline
\end{tabular}

Fuente: elaboración propia con datos de Rawson y Macpherson (2001).

El daño por heladas es diagnosticado al presentarse temperaturas inferiores a $-9{ }^{\circ} \mathrm{C}$.

$$
\mathrm{T}<-9^{\circ} \mathrm{Tm}<-9
$$

El daño por variación de temperaturas sucede cuando éstas rebasan los límites de temperatura base y temperatura óptima (To), según etapa (gráfica 1$)$. Si la temperatura (To Tm) está por debajo de la temperatura base (Tb) (sin llegar a ser helada), existirá daño por bajas temperaturas; si T o TM rebasan la temperatura óptima la causa serán las altas temperaturas.

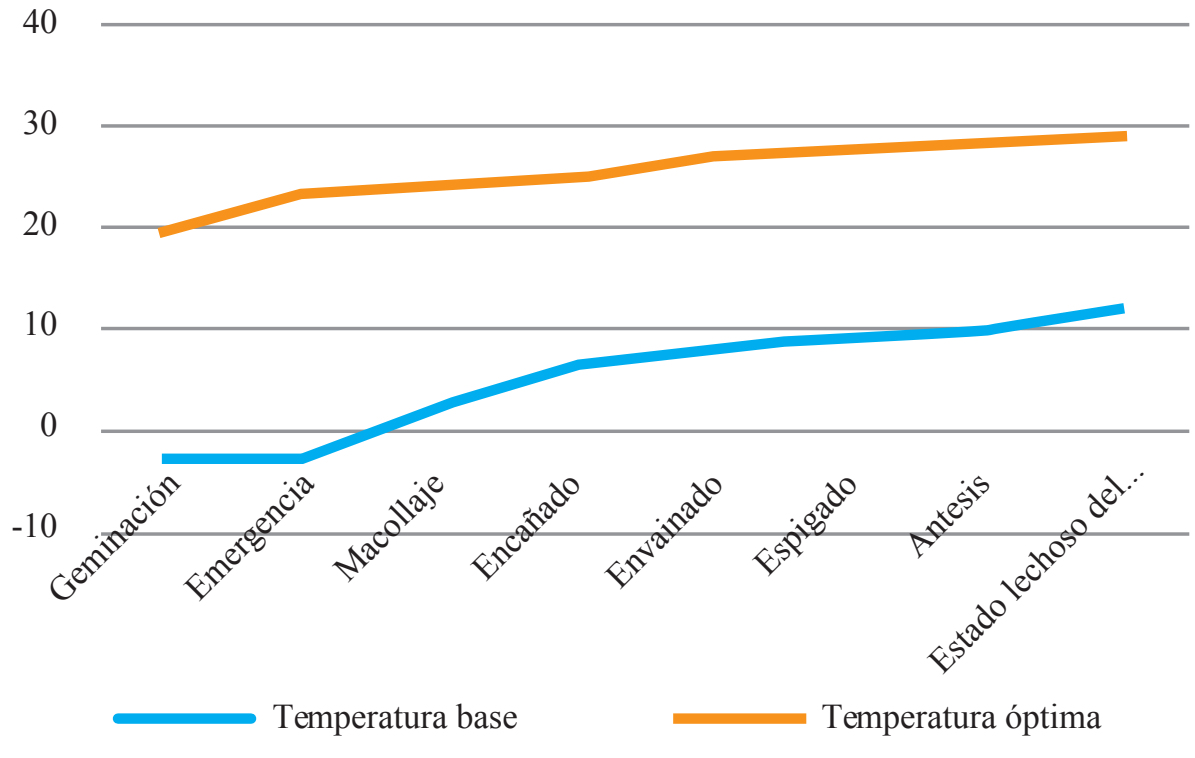

\section{GRÁFICA 1}

Temperatura base y temperatura óptima por etapa de desarrollo del trigo $\left({ }^{\circ} \mathrm{C}\right)$ Fuente: elaboración propia con datos de Rawson y Macpherson (2001). 
El daño por humedad se identifica al experimentar porcentaje de $\mathrm{H}$ con la relación siguiente:

$$
\mathrm{H}<=40 \text { y } \mathrm{H}>=70
$$

El daño por baja radiación solar surgirá al existir temperatura alta (como referencia la To según etapa) y con presencia de tiempo nublado (FG).

$$
(\mathrm{T}>\mathrm{To}) \text { o }(\mathrm{TM}>\mathrm{To}) \text { y }(\mathrm{FG}=1)
$$

El daño por lluvia o llovizna (RA) existirá si el factor climático se presenta consecutivamente por dos días o más o por vientos fuertes ( $\mathrm{V}$ o VM); se consideran vientos fuertes aquellos que muestra una velocidad de 50 a 61 $\mathrm{km} / \mathrm{h}$ o mayor en la escala de Beaufort (García et al., 2014).

Cada etapa fenológica responde después de dos o más días consecutivos de experimentar condiciones adversas. Como se observa, los umbrales de referencia difieren según la etapa y el factor climático. La posible causa de daño por etapa se menciona en la tabla 2.

TABLA 2

Causas de daño por etapa fenológica

\begin{tabular}{ll}
\hline Etapa fenológica Zadoks & \multicolumn{1}{c}{ Factores de daño } \\
\hline Germinación & Estrés hídrico, temperaturas, humedad \\
Emergencia & Estrés hídrico, heladas, temperaturas \\
Macollos & Estrés hídrico, heladas, temperaturas, baja radiación solar \\
Encañado & Estrés hídrico, heladas, temperaturas, baja radiación solar, humedad \\
Envainado & Estrés hídrico, heladas, temperaturas, baja radiación solar, humedad \\
Espigado & Estrés hídrico, heladas, temperaturas, baja radiación solar, lluvia o llovizna, humedad \\
Antesis & Estrés hídrico, heladas, temperaturas, baja radiación solar, lluvia o llovizna, viento fuerte \\
Grano lechoso & Estrés hídrico, heladas, temperaturas, baja radiación solar \\
\hline
\end{tabular}

Nota: causas relacionadas.

Fuente: Rawson y Macpherson (2001).

\subsection{Aprendizaje}

En este proceso se empleó un total de 53585 patrones climáticos (79\% del total), provenientes de América, Asia y Europa, almacenados en una matriz de entrada de $53585 \times 10$ (patrón de entrada $\times$ variable climática).

Por cada patrón, se realizó el análisis de daño fenológico (explicado en el apartado anterior) y sus resultados fueron concentrados en una nueva matriz de $53585 \times 8$ (diagnóstico/patrón $\times$ etapa fenológica), que constituye la salida deseada de la RNA, es decir, el resultado que deberá aprender por cada patrón climático.

Para lograrlo, se empleó el algoritmo de aprendizaje supervisado de Widrow y Hoff cuyo objetivo consiste en encontrar los pesos $(W)$, de cada patrón de entrenamiento $(X)$, además de sus umbrales de activación $(b)$ que minimicen el error cuadrático medio $(\mathrm{ecm})$ entre los datos de entrada y la salida deseada $(d)$. Considerando un factor de aprendizaje $(\mu)$, el algoritmo actualiza los $W$ a medida que van ingresando los $X$ y las $d$ para cada caso hasta obtener un error aceptable. La salida lineal $(y)$, el ecm y la actualización de pesos se obtienen mediante el siguiente algoritmo: 
a) Inicializar los pesos

b) Leer cada patrón de entrada $(X)$ y salida deseada $(d)$

c) Calcular la salida de la red $(y) \quad y_{j}=b_{k}+\sum_{i=1}^{n} W_{k i} * X_{i}$

d) Calcular el error cometido por el patrón $k \quad E_{k}=d_{k}-y_{k}$

$$
\text { Ecm }<E_{k}^{2}>=\frac{1}{L} \sum_{k=1}^{L} E_{k}^{2}=<\left(d_{k}-y_{k}\right)^{2}>
$$

e) Actualizar los pesos $w(t+1)=w(t)+2 \mu E_{k} x_{k}$

f) Repetir patrones del 2 al 5 para cada patrón de entrenamiento

g) Si el error es aceptable terminar el proceso; si no lo es, volver al paso 2.

El proceso concluyó al obtener resultados de eficiencia favorables; logró un ecm $=0$ para $93 \%$ de los patrones aprendidos.

Una vez concluido el aprendizaje, la precisión de la red fue validada. Para esto, se elaboró una matriz de validación que contiene 15100 patrones climáticos (provenientes de África y Oceanía). A partir de ella se construyó su respectiva salida deseada (diseño expuesto en el apartado anterior). La matriz de validación ingresó como entrada a la RNA, la cual emitió un diagnóstico que fue contrastado contra la salida deseada de esta matriz de validación y alcanzó $84 \%$ de resultados favorables.

\section{Sistema de Resultados}

Este sistema consiste en un bloque de código desarrollado en lenguaje científico que permite ingresar los datos de entrada a la RNA, recibir el diagnóstico y, con base en la etapa y los días en condiciones climáticas adversas, identificar la causa de daño, así como expresar los resultados al usuario en un lenguaje sencillo. La evaluación de la permanencia climática se basa en la expresión siguiente:

$$
T d_{f}=\sum_{i=1}^{n} d d_{f i}
$$

Donde:

$T d$ : Total de días consecutivos en los que se presenta el factor climático

$d d$ : Días con daño

$f$ : Identificador de factor climático

$n$ : Total de días evaluados

$i$ : Día evaluado

\section{Resultados}

Se analizaron en total 68685 registros climáticos diarios, de los cuales 79\% fue empleado para el aprendizaje de la RNA, cuyo proceso concluyó al alcanzar una eficiencia superior a 90\%. Para validar su precisión, se empleó el 
$21 \%$ restante de los patrones climáticos provenientes de África y Oceanía; alcanzó un diagnóstico correcto en más de $80 \%$ de los casos (cuadro 4).

CUADRO 4

Resultados de validación del evaluador inteligente

\begin{tabular}{|lcccc}
\hline Análisis & Registros empleados & $\begin{array}{c}\text { Registros evaluados } \\
\text { ecm }=\mathbf{0}\end{array}$ & $\begin{array}{c}\text { Porcentaje evaluado } \\
\text { ecm }=\mathbf{0}\end{array}$ & Regiones \\
\hline $\begin{array}{l}\text { Eficiencia de aprendizaje } \\
\text { de la RNA }\end{array}$ & 53585 & 49844 & $93 \%$ & $\begin{array}{l}\text { América, Asia } \\
\text { y Europa }\end{array}$ \\
$\begin{array}{l}\text { Validación/ precisión de } \\
\text { la RNA }\end{array}$ & 15100 & 12750 & $84 \%$ & $\begin{array}{l}\text { África y } \\
\text { Oceanía }\end{array}$ \\
\hline
\end{tabular}

Nota: resultados de validación de la RNA.

Fuente: elaboración propia.

Los registros empleados para el aprendizaje son diferentes a los empleados para la validación con el propósito de observar la capacidad de generalización de la red al entregar respuestas coherentes ante la entrada de datos nuevos.

\section{ANÁLISIS PROSPECTIVO}

El sector cerealista de unas décadas a la fecha enfrenta la incertidumbre ocasionada por el cambio climático a causa de los niveles cambiantes de intensidad y frecuencia, que a su vez dan lugar a una más: la seguridad alimentaria basada en la tarea de mantener niveles óptimos de rendimiento y calidad en los cultivos.

Con una visión a futuro, las acciones de adaptación hoy en día tienen como premisa el cuidado al planeta, el manejo de cultivo tradicional y la implementación de estrategias y tecnologías sustentables que fortalezcan su resiliencia (Gutiérrez et al., 2018). No obstante, las tendencias mundiales son desafortunadas en algunos aspectos (tabla 3).

TABLA 3

Tendencias mundiales del sector cerealista ante el cambio climático

\begin{tabular}{|ll}
\hline Tendencias & Aspecto \\
\hline Incremento en la demanda de trigo & Social \\
Desarrollo e implementación de tecnologías y estrategias de adaptación no sustentables & Tecnológico \\
Reducción de la producción, rendimiento y calidad del cultivo de trigo & Económico \\
Pérdidas & \\
Incremento de la temperatura & Ambiental \\
Construcción de nuevas políticas públicas de apoyo al medioambiente en la agricultura & Político \\
\hline
\end{tabular}

Fuente: elaboración propia con datos de Reeves et al., 2016; Jones y Phillips, 2016; FAO, 2002.

Considerando estas tendencias, así como el pronóstico de producción de trigo mundial hacia 2050 y años posteriores, el panorama es desalentador. El sector cerealista, al depender por completo del clima, es altamente vulnerable y la inseguridad alimentaria será la principal implicación de no contar con estrategias de adaptación eficaces y sustentables (Reeves et al., 2016). 
El reto global consiste en desarrollar iniciativas orientadas a reducir esta vulnerabilidad e incertidumbre ante consecuencias reales o esperadas del cambio climático (Eggleston et al., 2006). Para lograrlo, el monitoreo y evaluación del cultivo desde la siembra hasta la cosecha representa una actividad que es fundamental para el agricultor, quien, sin embargo, continúa empleando métodos tradicionales no probabilísticos que no permiten medir su margen de error.

Por lo anterior, el uso de tecnología inteligente de alta precisión capaz en el manejo de incertidumbre y con poder de generalización, tal como la propuesta que se expone, representa una alternativa de apoyo al cumplimiento de estos objetivos adecuada incluso en la evaluación grandes extensiones de cultivo y, por las tendencias climáticas mundiales de los últimos 27 años, constituye una estrategia tecnológica eficaz para la identificación de etapas vulnerables desde la siembra hasta la madurez del cultivo.

El diagnóstico emitido apoyará al tomador de decisiones a diseñar acciones de prevención e intervención enfocadas en los requerimientos específicos de la planta en cualquier ambiente que se encuentre y así posibilitar la construcción de planes de contingencia y acciones estratégicas oportunas que contribuyan a evitar pérdidas, ya sea de rendimiento o de calidad del trigo, y a su adaptación ante el cambio climático, además de fortalecer la seguridad alimentaria y el desarrollo económico a corto, mediano y largo plazo.

\section{Conclusiones}

La RNA propuesta emitió diagnósticos con $84 \%$ de precisión: el sistema de resultados los confirmó. Por tanto, el modelo evaluador inteligente se considera una estrategia tecnológica robusta y adecuada para evaluar el daño en cultivo de trigo e identificar su causa según etapa de desarrollo.

La RNA fue validada con registros diferentes a aquellos con los cuales se entrenó. Alcanzó también un nivel de precisión alto que evidencia su capacidad de generalización y de diagnosticar cultivos de trigo ubicados en diferentes zonas del mundo.

La propuesta ofrece al agricultor (experto o inexperto) una fuente de información precisa que apoya la toma de decisiones estratégica capaz de fusionar el manejo de cultivo tradicional con la precisión de los modelos inteligentes actuales.

\section{REFERENCIAS}

Arkeman, Y., B. Seminar, K., \& J. Lahay, R. (2014). An intelligent system for early detection of food crisis and spatial-based decision making of potential land evaluation for food production. Mundo-Indonesia.

Arnell, N. W. (2016). The global-scale impacts of climate change: The QUEST-GSI project. Climatic Change, 134(3), 343-352.

Asseng, S., Ewert, F., Martre, P., Rötter, R. P., Lobell, D. B., Cammarano, D., \& Reynolds, M. P. (2015). Rising temperatures reduce global wheat production. Nature Climate Change, 5(2), 143-147.

Boutraa, T., Akhkha, A., \& Al-Shoaibi, A. K. (2015). Evaluation of growth and gas exchange rates of two local saudi wheat cultivars grown under heat stress conditions. Pakistan Journal of Botany, 47(1), 27-34.

Butt, T., Angerer, J., Dyke, P., Kim, M., Kaitho, R., \& Stuth, J. (2016). Agricultural climate change impact: General concerns and findings from Mali, Kenya, Uganda, and Senegal.

Crimp, S. J., Zheng, B., Khimashia, N., Gobbett, D. L., Chapman, S., Howden, M., \& Nicholls, N. (2016). Recent changes in southern Australian frost occurrence: Implications for wheat production risk. Crop and Pasture Science, 67(8), 801-811 
Eggleston, S., Buendia, L., \& Miwa, K. (2006). 2006 IPCC guidelines for national greenhouse gas inventories. Waste. Kanagawa, JP: Institute for Global Environmental Strategies.

FAO (Food and Agriculture Organization) (2002). Agricultura mundial: hacia los años 2015/2030. Informe resumido. Disponible en http://www.fao.org/docrep/004/y3557s/y3557s08.htm\#l.

Field, C., Barros, V., Dokken, D., Mach, K., Mastrandrea, M., \& Bilir, T. (2014). Cambio climático 2014: impactos, adaptación y vulnerabilidad. Quinto Informe de Evaluación (GTII IE5) del IPCC.

Frederiks, T. M., Christopher, J. T., Sutherland, M. W., y Borrell, A. K. (2015). Post-head-emergence frost in wheat and barley: Defining the problem, assessing the damage, and identifying resistance. Journal of Experimental Botany, 66(12), 3487-3498.

Gallo, A. (2015). Assessment of the climate change impact and adaptation strategies on Italian cereal production using high resolution climate data.

García, M., Ulloa, H., Ramírez, H., Fuentes, M., Arias, S. y Espinoza, M. (2014). Comportamiento de los vientos dominantes y su influencia en la contaminación atmosférica en la zona metropolitana de Guadalajara, Jalisco, México. Revista Iberoamericana de Ciencias, 1, 97-116.

Gaydon, D. S., Wang, E., Poulton, P. L., Ahmad, B., Ahmed, F., Akhter, S., \& Choudhury, B. U. (2017). Evaluation of the APSIM model in cropping systems of Asia. Field Crops Research, 204, 52-75.

Gutiérrez, S. S. M., Palacios, A. T., Ruiz-Vanoye, J. A., \& Pérez, S. L. (2018). Sustainable and technological strategies for basic cereal crops in the face of climate change: A literature review. African Journal of Agricultural Research, 13(5), 220-227.

Ihsan, M. Z., El-Nakhlawy, F. S., Ismail, S. M., \& Fahad, S. (2016). Wheat phenological development and growth studies as affected by drought and late season high temperature stress under arid environment. Frontiers in Plant Science, 7.

Ji, H., Xiao, L., Xia, Y., Song, H., Liu, B., Tang, L., \& Liu, L. (2017). Effects of jointing and booting low temperature stresses on grain yield and yield components in wheat. Agricultural and Forest Meteorology, 243, 33-42.

Jones, A. W., \& Phillips, A. (2016). Historic food production shocks: Quantifying the extremes. Sustainability, 8(5), 427.

Lv, H., Lei, T., Huang, X. L., \& Zhang, Y. K. (2016). Application of an improved grey neural network in grain yield Prediction.

Nieves-Hurtado, A., y Domínguez-Sánchez, F. C. (2009). Probabilidad y estadística para ingeniería un enfoque moderno. México: McGraw-Hill.

Palmer-Pol, A., \& Montaño-Moreno, J. J. (1999). ¿Qué son las redes neuronales artificiales? Aplicaciones realizadas en el ámbito de las adiciones. Adicciones, 11(3), 243-255.

Pimentel, A. J. B., Rocha, J. R. D. A. S., Souza, M. A. D., Ribeiro, G., Silva, C. R., \& Oliveira, I. C. M. (2015). Characterization of heat tolerance in wheat cultivars and effects on production components. Revista Ceres, 62(2), 191-198.

Rawson, H. M. y Macpherson, G., (2001). Trigo regado: manejo del cultivo. Food \& Agriculture Organization. Disponible en http://www.fao.org/docrep/006/x8234s/x8234s00.htm\#Contents

Reeves, T. G., Thomas, G., y Ramsay, G. (2016). Ahorrar para crecer en la práctica: maíz, arroz, trigo. Guía para la producción sostenible de cereales.

Reynolds, M. P., Quilligan, E., Aggarwal, P. K., Bansal, K. C., Cavalieri, A. J., Chapman, S. C., \& Jagadish, K. S. (2016). An integrated approach to maintaining cereal productivity under climate change. Global Food Security, 8, 9-18. 
Sanad, M. N., Campbell, K. G., \& Gill, K. S. (2016). Developmental program impacts phenological plasticity of spring wheat under drought. Botanical Studies, 57(1), 35.

Serrano, M. M. (2015). Cambio climático y la gran transformación del siglo XXI: hacia un futuro sostenible. Derecho \& Sociedad, 35, 146-151.

Singh, M. K., \& Singh, B. R. (2015). Observation and temperature changes: Warming of the climate system and future global warming in 21 st century. SAMRIDDHI: A Journal of Physical Sciences, Engineering and Technology. https://doi.org/10.18090/samriddhi.v5i2.1531

Trnka, M., Hlavinka, P., \& Semenov, M. A. (2015). Adaptation options for wheat in Europe will be limited by increased adverse weather events under climate change. Journal of The Royal Society Interface, 12(112), 20150721.

Yegnanarayana, B. (2009). Artificial neural networks. PHI Learning Pvt. Ltd.

Zheng, Z., Cai, H., Yu, L., \& Hoogenboom, G. (2017). Application of the CSM-CERES-W'heat model for yield prediction and planting date evaluation at guanzhong plain in Northwest China. Agronomy Journal, 109 (1), 204-217.

\section{BY-NC-ND}

